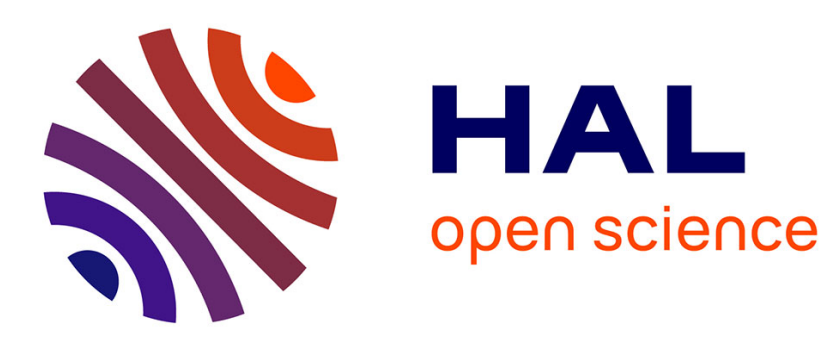

\title{
A study of energy conversion during Nd:YAG laser ablation of metal surfaces in air by means of a laser beam deflection probe
}

\author{
J. Diaci, J. Mozina
}

\section{- To cite this version:}

J. Diaci, J. Mozina. A study of energy conversion during Nd:YAG laser ablation of metal surfaces in air by means of a laser beam deflection probe. Journal de Physique IV Proceedings, 1994, 04 (C7), pp.C7-737-C7-740. 10.1051/jp4:19947173 . jpa-00253234

HAL Id: jpa-00253234

https://hal.science/jpa-00253234

Submitted on 1 Jan 1994

HAL is a multi-disciplinary open access archive for the deposit and dissemination of scientific research documents, whether they are published or not. The documents may come from teaching and research institutions in France or abroad, or from public or private research centers.
L'archive ouverte pluridisciplinaire HAL, est destinée au dépôt et à la diffusion de documents scientifiques de niveau recherche, publiés ou non, émanant des établissements d'enseignement et de recherche français ou étrangers, des laboratoires publics ou privés. 


\title{
A study of energy conversion during Nd:YAG laser ablation of metal surfaces in air by means of a laser beam deflection probe
}

\author{
J. Diaci and J. Mozina \\ University of Ljubljana, Faculty of Mechanical Engineering, Askerceva 6, P.O. Box 394, \\ 61000 Ljubljana, Slovenia
}

\begin{abstract}
We measure shock wavefront transition times of optoacoustic (OA) transients generated in air during laser ablation and employ the solution of the point explosion model to determine blast energy of the OA transients. We examine the dependence of OA energy conversion efficiency on laser energy and pulse duration.
\end{abstract}

\section{INTRODUCTION}

Recent experimental evidence $\left({ }^{1-3}\right)$ indicates that strong OA waves generated in the surrounding air during laser ablation of a solid surface bear much resemblance to the so called blast waves produced by explosions. Several features of spherical OA transients have been explained $\left({ }^{3}\right)$ by using the point explosion model $\left({ }^{4}\right)$, where an instant deposition of blast energy $E$ in a small volume of a perfect gas is assumed.

In this contribution we make use of the fact, known in the physics of explosions $\left({ }^{4}\right)$, that the shock front trajectory of a blast wave is primarily determined by the blast energy $E$ coupled into the wave and that it is possible to determine $E$ by measurement of the shock trajectory. Employing a laser beam deflection probe we detect OA transients generated in air during Nd:YAG laser ablation of metallic surfaces. We measure their shock wavefront transit time $t_{s}$ across the distance $r_{s}$ between the probe beam axis and the irradiated surface, the acoustic wave transit time $t_{a}$ for the same distance, pressure $p_{0}$ and temperature $T_{0}$ of the ambient air. Using this data and the theoretical shock trajectory based on a numerical solution $\left(^{5}\right)$ of the point explosion model we determine the blast energy. We examine the dependence of blast energy and energy conversion efficiency (the ratio of blast energy to incident laser energy) on laser energy and pulse duration. We analyze measurement uncertainty of this method and compare it with the uncertainty of a similar method $\left({ }^{6}\right)$ which is based on measurement of duration $t_{+}$of the compressive phase of blast wave instead of the shock transit time $t_{s}$.

\section{EXPERIMENT}

We ablated the samples by two Nd:YAG lasers of $1.06 \mu \mathrm{m}$ wavelength with pulses of $12 \mathrm{~ns}$ and $60 \mathrm{~ns}$ duration and beams focused to a spot of $0.5 \mathrm{~mm}$ in diameter on the ablated surface (FIG. 1). The sample assembly and the focusing lens were mounted together on a mechanical translator allowing precise setting of the distance $r_{s}$ while maintaining constant focusation of the ablation beam. We detected deflection of the probe beam due to the passage of a OA wave by means of a quadrant photodetector with a $2.5 \mathrm{MHz}$ bandwidth. By changing the incident laser energy $E_{l}$ and pulse duration we acquired a set of $O A$ signals for each sample. We started with the highest available energy and irradiated a spot on the sample surface with laser pulses of decreasing energy until the OA signal would disappear in noise. All signals were acquired in the single shot mode. Before the ablation experiment we calibrated the monitoring energy meter by means of another (traceable) calibrated energymeter with the probe in place of the sample. 


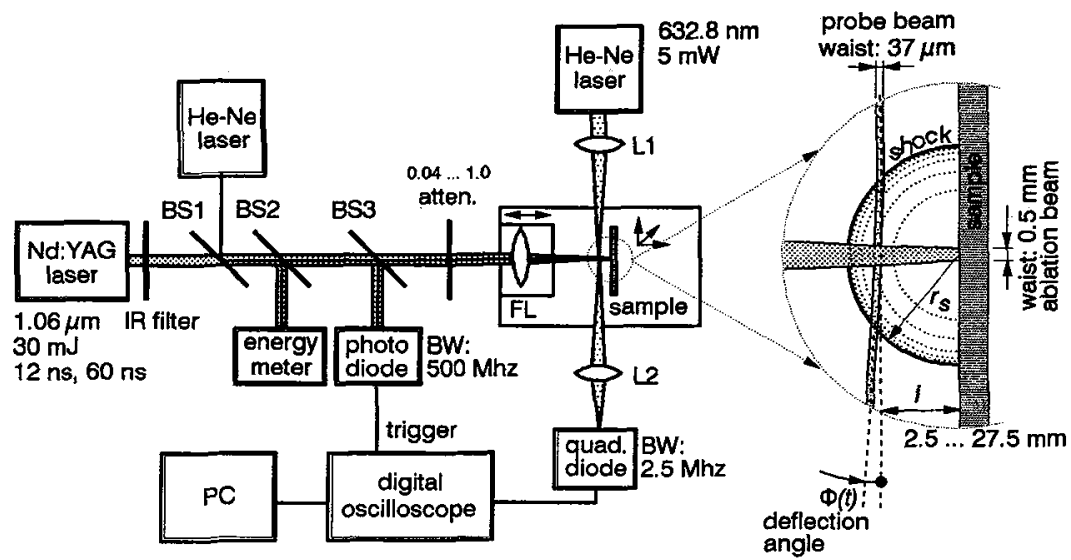

\section{FIG. 1 Experimental set-up}

Most OA transients were detected in the weak shock range (far from the OA source). In this case, the transfer function of the laser probe can be adequately modeled $\left.{ }^{7}\right)$ and its effect on the measured signal can be eliminated by means of deconvolution. The signal waveforms obtained after this processing agree very well with the theoretical density waveforms calculated by using a numerical solution $\left({ }^{4,5}\right)$ of the point explosion model. Even with the signals detected in the intermediate shock range (e.g. FIG. 2), which exhibit substantial nonlinearities, the deconvolution procedure gives remarkably good results (FIG. 3 ).

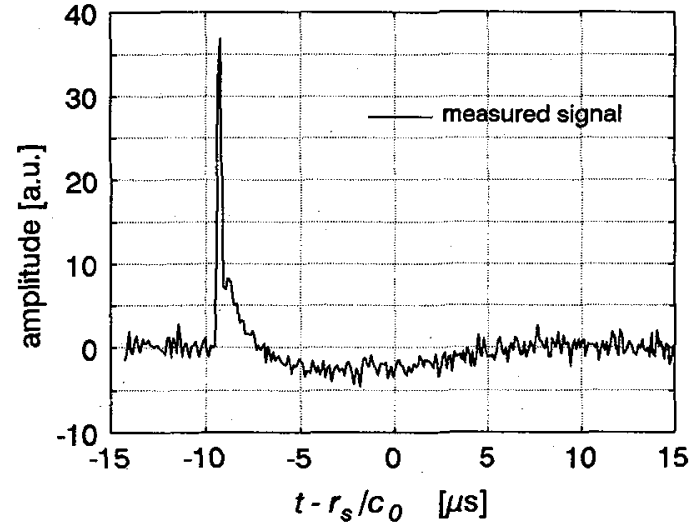

FIG. 2 A typical measured signal (steel sample)

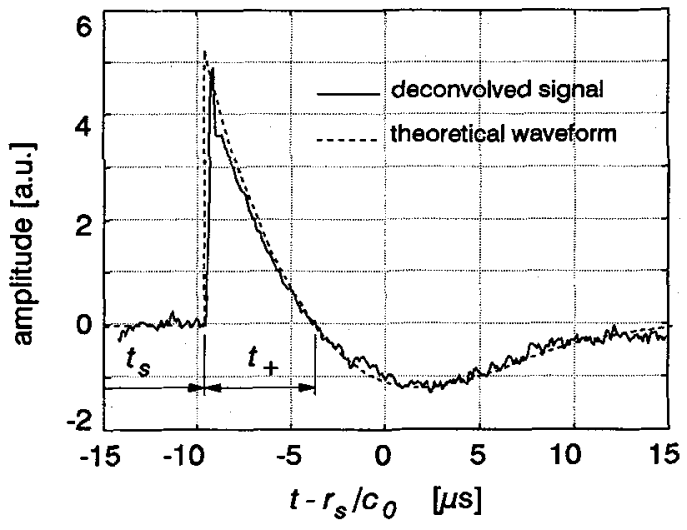

FIG. 3 Signal of FIG.2 deconvolved with the transfer function of the laser probe (solid line) and the corresponding theoretical density waveform (dashed line)

\section{THEORY}

In the intermediate and weak shock range, only a numerical solution of the point explosion model exists which is commonly expressed in terms of dimensionless space $\xi=r / r_{c}$ and time $\tau=t / t_{c}$ coordinates with characteristic scaling parameters $(4,5)$ :

$$
\left.r_{c}=\left(\alpha E / p_{0}\right)^{1 / 3} \quad \text { and } t_{c}=r_{c} / c_{0}, \quad \text { (for air: } \gamma=1.4 \text { and } \alpha=1.175\right)\left({ }^{5}\right)
$$

where $c_{0}=\sqrt{\gamma R T_{0}}$ is the sound velocity of the undisturbed gas while $p_{0}$ and $T_{0}$ are the ambient pressure and temperature respectively. 
In principle, any theoretical function $f$ of the form $\tau=f\left(\xi_{s}\right)$, giving some characteristic time $\tau$ of the dimensionless waveform at the dimensionless distance $\xi_{s}$ from the source, can be used to determine blast energy $E$ from the measured data. We employ $\left({ }^{6}\right)$ two such functions (FIG. 4): the shock trajectory $\tau_{s}=f_{1}\left(\xi_{s}\right)$, and the dependence of the compression duration $\tau_{+}=f_{2}\left(\xi_{s}\right)$ on $\xi_{s}\left({ }^{5}\right)$. In both cases, the functions are constructed from the numerical solution by means of spline interpolation. In order to save space, we shall consider here only the shock trajectory. The formulae pertinent to the other function can be obtained from the stated ones by merely exchanging $\tau_{s}$ with $\tau_{+}, f_{1}$ with $f_{2}$, and $t_{s}$ with $t_{+}$.

By replacing the function argument $\xi_{s}$ with $\xi_{s}=r_{s} / r_{c}=c_{0} t_{a} / r_{c}$ and the function value with $\tau_{s}=t_{s} / t_{c}=c_{0} t_{s} / r_{c}$ we get the equation:

$$
c_{0} t_{s} / r_{c}=f_{1}\left(c_{0} t_{a} / r_{c}\right)
$$

which we solve numerically for $r_{c}$ and then use eq. (1) to determine blast energy $E$. The energy $E_{h}$ contained in a hemispherical wave is assumed to be a half of the blast energy that would produce the same mechanical effect in the spherical case: $E_{h}=E / 2$.

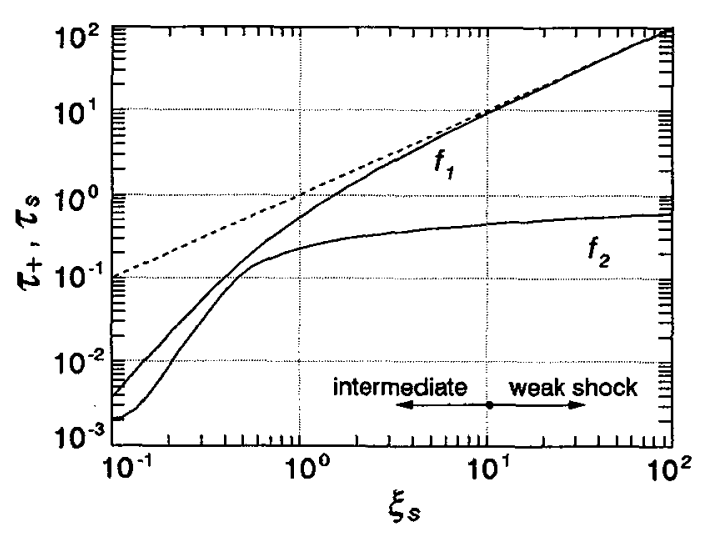

FIG. 4 Theoretical functions employed to determine blast energy $E_{h}$

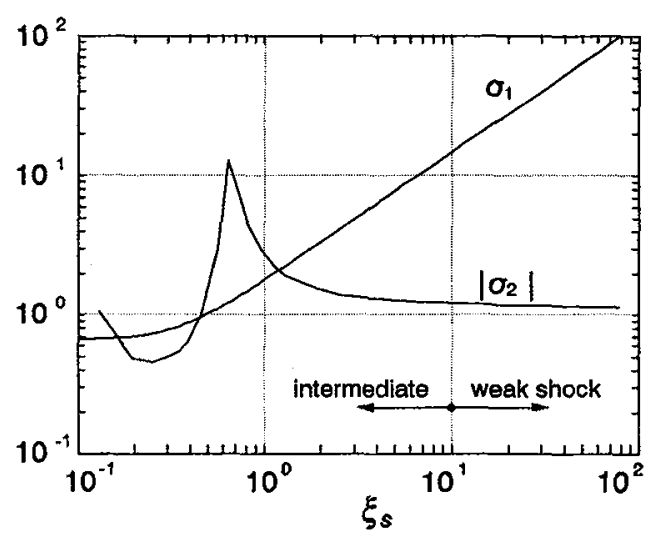

FIG. 5 Theoretical functions employed to determine measurement uncertainty of $E_{h}$

In order to assess how the uncertainties ("errors") of the measured variables $\left(p_{0}, t_{a}, t_{s}, T_{0}\right)$ affect the uncertainty of blast energy we differentiate the equations employed:

$$
\begin{array}{ll}
E_{h}=p_{0} r_{c}^{3} / 2 \alpha & \Rightarrow \mathrm{d} E_{h} / E_{h}=\mathrm{d} p_{0} / p_{0}+3 \mathrm{~d} r_{c} / r_{c}, \\
c_{0}=\sqrt{\gamma R T_{0}} & \Rightarrow \mathrm{d} c_{0} / c_{0}=\mathrm{d} T_{0} / 2 T_{0}, \\
\tau_{s}=f_{1}\left(\xi_{s}\right) & \Rightarrow \mathrm{d} \tau_{s} / \tau_{s}=\left[\xi_{s} f_{1}^{\prime}\left(\xi_{s}\right) / f_{1}\left(\xi_{s}\right)\right] \mathrm{d} \xi_{s} / \xi_{s}, \\
\tau_{s}=c_{0} t_{s} / r_{c} & \Rightarrow \mathrm{d} \tau_{s} / \tau_{s}=\mathrm{d} c_{0} / c_{0}+\mathrm{d} t_{s} / t_{s}-\mathrm{d} r_{c} / r_{c}, \\
\xi_{s}=c_{0} t_{a} / r_{c} & \Rightarrow \mathrm{d} \xi_{s} / \xi_{s}=\mathrm{d} c_{0} / c_{0}+\mathrm{d} t_{a} / t_{a}-\mathrm{d} r_{c} / r_{c},
\end{array}
$$

and eliminate the auxiliary variables. Analysis of the resulting form:

$$
\frac{\mathrm{d} E_{h}}{E_{h}}=\frac{\mathrm{d} p_{0}}{p_{0}}+3\left(\sigma_{1}+1\right) \frac{\mathrm{d} t_{a}}{t_{a}}-3 \sigma_{1} \frac{\mathrm{d} t_{s}}{t_{s}}-\frac{3}{2} \frac{\mathrm{d} T_{0}}{T_{0}}
$$

where: $\sigma_{1}=\frac{1}{\xi_{s} f_{1}^{\prime}\left(\xi_{s}\right) / f_{1}\left(\xi_{s}\right)-1}$,

shows (FIG. 5) that the use of shock trajectory $f_{1}$ promises good results (small uncertainties) only in the strong and intermediate shock region (where $\sigma_{1} \approx 1$ ). In the weak shock region, however, $\sigma_{1}$ can be quite large implying that small uncertainties of $t_{a}$ and $t_{s}$ give rise to large uncertainties of $E_{h}$. In this region, function $f_{2}$ (compression duration) with $\sigma_{2}$ asymptotically decaying to 1 offers a much better performance. This potential of $f_{2}$ in the weak shock range, however, might be difficult to exploit fully as it might require higher fidelity of the measurement system and much more sophisticated signal processing. 


\section{RESULTS}

In FIG. 6 we illustrate some characteristic observations on OA energy conversion efficiency. The efficiency increases monotonically with the increase of incident laser energy $E_{l}$. The steepness of the efficiency rise with $E_{l}$ decreases above some threshold energy. The efficiency curves thus exhibit two characteristic regions: intense efficiency increase at low energies $E_{l}$ and gradual increase (saturation) at high $E$. With the longer $(60 \mathrm{~ns})$ ablation pulses the region of the efficiency rise is steeper and starts at higher energy. The highest efficiencies observed in this experiments were around $20 \%$ and did not depend much on the irradiated material or pulse duration. In the saturation region, we observed generally only minor pulse to pulse efficiency variations. Below that these variations were relatively more intense and depended very much on the state of the surface. No systematic dependence of blast energy on $r_{s}$ was observed and we take this as an evidence that the model applies well.
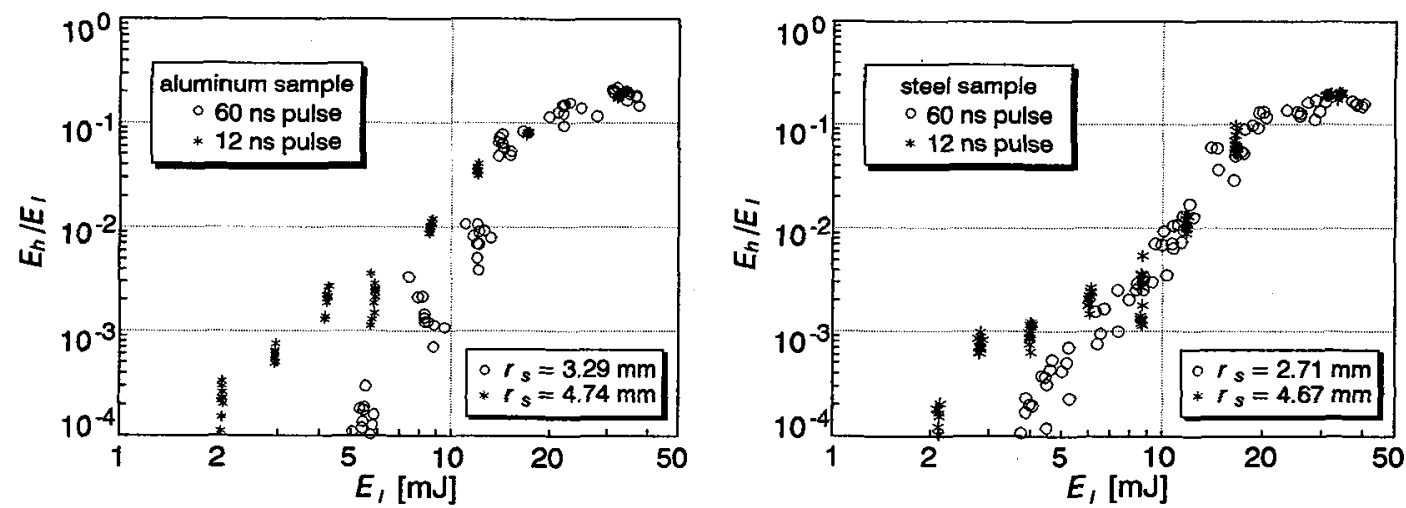

Fig. 6 Energy conversion efficiency vs. incident laser energy

In conclusion, most recent optoacoustic studies of the ablation process use the OA signal amplitude as the relevant $O A$ parameter. Comparison of the ablation data in terms of OA amplitude could be a problem because it depends on several experimental factors. In such a case, the use of blast energy would be the solution.

\section{References}

[1] Dyer P.E. and Sidhu J., J. Appl. Phys. 64 (1988) 4657.

2. Zyung T., Kim H., Postlewaite J.C., and Dlott D.D., J. Appl. Phys. 65 (1989) 4548.

3) Diaci J. and Možina J., Appl Phys A: Solid Surf 55 (1992) 352.

44 Sedov L.I., Similarity and dimensional methods in mechanics (Nauka, Moscow, 1972) (in Russian), Chap. IV.

[5] Okhotsimskii D.E. and Vlasova Z.P., J. Vychisl. Matematiki i Matem. Fiziki 2, (1962) 107 (in Russian).

[6] Diaci J. and Možina J., Ultrasonics International '93 Conference Proceedings (ButterworthHeinemann, Guildford, 1993) pp. 787-790.

[7] Diaci J., Rev. Sci. Instrum. 63 (1992) 5306. 